\title{
Impact of a Palliative Care Course on Pre-Registration Nursing Students' Palliative Care Knowledge
}

\author{
Nahyeni Bassah*, John Ngunde Palle \\ Department of Nursing, University of Buea, South-West Region, Cameroon \\ Email address: \\ nahyenibassah@yahoo.com (N, Bassah),ngunde_pal@yahoo.co.uk (J. N. Palle) \\ ${ }^{*}$ Corresponding author
}

\section{To cite this article:}

Nahyeni Bassah, John Ngunde Palle. Impact of a Palliative Care Course on Pre-Registration Nursing Students' Palliative Care Knowledge. Central African Journal of Public Health. Vol. 5, No. 2, 2019, pp. 58-64. doi: 10.11648/j.cajph.20190502.11

Received: June 7, 2018; Accepted: February 1, 2019; Published: February 28, 2019

\begin{abstract}
In resource-poor settings some preregistration nursing curricula, do not include any palliative care content, and practising nurses, both newly graduated and student nurses have limited knowledge about palliative care. The aim of this study was to evaluate the impact of a palliative care course on Cameroonian preregistration nursing students' palliative care knowledge. The study employed a longitudinal quasi-experimental pretest/posttest design. A 30 hours classroom based palliative care course, underpinned by the experiential learning theory was delivered to second and third year nursing students in a University in Cameroon. An evaluation of the impact of the course on students' palliative care knowledge was conducted via a pretest/posttest survey. Data was analysed using both descriptive and inferential statistics. The study revealed very poor palliative care knowledge among preregistration nursing students, with a mean pretest score of 5.72/20 (Standard deviation of 2.54; Confidence Interval: 5.11-6.34). After the palliative care course there was a statistically significantly improvement in students' overall palliative care knowledge, with a posttest score of $11.36(\mathrm{SD}=2.03$, CI 10.85-11.87). Demographic factors like students' level in the nursing course and age were seen to be associated with students' pre-course scores ( $\mathrm{P}=0.002$ and 0.027 respectively), but no demographic factor was implicated in the posttest score. There is therefore a need for curriculum revision to include palliative care content in the preregistration nurse training curricula of the pilot University.
\end{abstract}

Keywords: Palliative Care Education, Pre-Registration Nursing Education, Resource-Poor Settings

\section{Introduction}

Nurses constitute the largest number of healthcare professionals in most countries and may be the only healthcare provider that patients will have access to in some remote areas of resource-poor countries. Given the role that nurses play in the healthcare system in resource-poor countries, they will likely encounter someone with a chronic/life-threatening condition who requires palliative care [1]. Inadequate education of preregistration nursing students in palliative care in resource-poor countries therefore may mean that they graduate from the program unprepared for their future role as palliative care providers [2-3]. Consequently, patients may not receive good quality palliative and end of life nursing care. There is therefore a need for every nurse to have access to adequate palliative care education.
A good number of studies have been conducted on the impact of a palliative care education on preregistration nursing students' palliative care knowledge and attitude, however, these have been in resource rich countries like the UK, USA and Canada [4-6]. These studies suggests that improvements in attitudes towards care of dying patients and their families is achievable. However, although attitudinal competencies are important in palliative care nursing, they are insufficient without adequate palliative care knowledge and psychomotor skills [7-8]. There is thus need for more research to enhance understanding of how palliative care education impact on nursing students' knowledge and skills. This study therefore sought to understand whether a 30 hour classroom based palliative care course delivered by nurse educators and palliative care nurses in Cameroon could improve the palliative care knowledge of preregistration nursing students. 


\section{Method}

\subsection{Study Design}

This study employed a longitudinal quasi-experimental study design, specifically, the single group pretest posttest design. The primary outcome measure was palliative care knowledge. In this study, a palliative care course was delivered to 2 nd and 3 rd year nursing students in a University in Cameroon, by nurse educators, a chaplain, and specialist palliative care nurses in Cameroon. The course was a 30 hours classroom based palliative care course, underpinned by the experiential learning theory. After completing the course, students undertook their regular clinical placement, in medical-surgical care settings, 2 days in a week for two months.

Baseline assessment of the outcome measures was conducted on the first day of the course, prior to the start of the lectures about palliative care. A follow up assessment was conducted at the end of students' second semester placement experience, approximately two months after the last day of the course, to allow completion of the experiential learning cycle by Kolb [9] as well as minimise the practice effect [10].

\subsection{Data Collection Method}

The data for this study was collected using a questionnaire consisting of the palliative care quiz for nurses (PCQN), and a demographic subscale. The demographic questionnaire was to collect information on participants' characteristics. The validated Palliative Care Quiz for Nursing (PCQN) by Ross et al. [11] was used to assess change in students' palliative care knowledge. The PCQN is a 20 -item; true, false and 'I don't know' test instrument that can be used for the assessment of knowledge in palliative care nursing.

\subsection{Data Analysis}

The paired t-test was used to calculate the change in students' palliative care knowledge from pretest score to posttest score, and to examine the significance of this change. For this analysis, scores on the PCQN scale were calculated as the number of correct versus incorrect answers. 'I don't know' and unanswered questions were counted as wrong answers. A new variable, called 'dffscore' was created, which was the change score of each student; subtracting the pretest score from the posttest score. A histogram of the responses for the pretest, posttest and dffscore was also created to check the distribution of the data. Given that these distributions were normal and the variable under consideration was a continuous variable based on the same sample, the t-test was found to be a suitable test in this case.

McNemar's test, a nonparametric test, was used to assess change on the individual items on the PCQN scale because the variables were binary categorical outcomes variables based on the same sample. The objective of this analysis was to assess the proportion of students who knew before to the proportion of students who knew after. The McNemarBowker statistic was also conducted to assess how the course had impacted on students' knowledge of the various subthemes of the knowledge questionnaires including: the principles of palliative care, pain and symptom management and psychosocial and spiritual care, as partitioned by the authors of this instrument [11].

\subsection{Ethical Considerations}

Ethical approval for this study was obtained from the University of Buea Institutional Review Board.

\section{Results}

\subsection{Demographic Profile of the Respondents}

Sixty-nine students completed the pretests and 64 $(92.75 \%)$ completed the posttest. The 69 students who took the pretest were those who started the course on the first day while the 64 students for the posttest were those who completed all five sessions of the course. Of the 69 students who took part in the pretest, $31(44.93 \%)$ were second year students and $38(54.07 \%)$ were in the third year. Most $[37(53.6 \%)$ of them were 21 years and above and a majority [59(85.5\%)] were females. A greater majority of these students [27 (39.1\%)] were Catholics. At baseline, 50(72.5\%) students reported that they had no prior experience in caring for a dying person and 52(75.4\%) stated they had not received any prior education in palliative care (Table 1).

Table 1. Demographic information of participants.

\begin{tabular}{|c|c|c|c|}
\hline Variable & Categories & Frequency $(n=69)$ & Percentage (\%) \\
\hline \multirow{2}{*}{ Gender } & Male & 10 & 14.49 \\
\hline & Female & 59 & 85.51 \\
\hline \multirow{2}{*}{ Level in nursing program } & Year 2 & 31 & 44.93 \\
\hline & Year 3 & 38 & 54.07 \\
\hline \multirow{2}{*}{ Age } & $18-20$ years & 32 & 46.4 \\
\hline & $>20$ years & 37 & 53.6 \\
\hline Previous experience in care of the dying & Yes & 19 & 27.54 \\
\hline \multirow{2}{*}{ Previous education in palliative care $\mathrm{n}(\%)$} & Yes & 17 & 24.64 \\
\hline & No & 52 & 75.36 \\
\hline \multirow{3}{*}{ Religion n (\%) } & Catholic & 27 & 39.13 \\
\hline & Presbyterian and Baptist & 24 & 34.78 \\
\hline & Others & 18 & 26.09 \\
\hline
\end{tabular}




\subsection{Students' Pre-Course Palliative Care Knowledge}

Before the course the overall palliative care knowledge of this group of students was quite poor, with a mean score of 5.72/20 (Standard deviation of 2.54; Confidence Interval: 5.11-6.34). The highest score achieved was $13 / 20$ and the lowest was $1 / 20$.

With regards to the individual items on the PCQN, no student knew before the course that placebos are not appropriate in the treatment of pain in palliative care. Only 3 (4.3\%) knew that 'the philosophy of palliative care is compatible with that of aggressive treatment'; and only 4 $(5.8 \%)$ knew that 'drug addiction is not a major problem when morphine is used on a long-term basis for the management of pain'.

Nevertheless, there were a few questions where a considerable number of students could answer correctly before the course. Up to $63(91.3 \%)$ students knew that the manifestations of chronic pain are different from those of acute pain. In addition, $40(58 \%)$ knew that the provision of palliative care does not require emotional detachment, and up to $38(55.1 \%)$ student knew that suffering and physical pain are not synonymous.

\subsection{Students' Posts-Course Palliative Care Knowledge}

After the course, the mean score of the students' palliative care knowledge was $11.36(\mathrm{SD}=2.03$, CI $10.85-11.87)$. Scores ranged from $3 / 20$ to $18 / 20$. Overall, there was a statistically significant improvement in the palliative care knowledge of this student group from pretest to posttest (Paired sample t-test; $\mathrm{P}=0.000$ ).

With regard to the individual items on the PCQN, the number of students, who answered correctly in the posttest, was higher for 19 of the 20 questions. The only exception was for the item: 'the provision of palliative care requires emotional detachment', where 40 students knew the right response before the course, but this dropped to 38 students, after the course.

There were three questions where a considerable number of students who did not know the correct response before the course, knew it after. Thirty-one (48.4\%) students who wrongly identified in the pretest that the use of placebos are appropriate in the treatment of some types of pain, correctly identified in the posttest that they are not appropriate. Moreover, up to $42(65.6 \%)$ students who did not know before, knew after the course that individuals who are taking opioids should also follow a bowel regimen, and 36(56.3\%) new students could identify after the course that tramadol is not an effective analgesic for the control of chronic pain.

However, there were still questions where a good number of students did not know the correct answer after the course. Most students [55(85.9)] still struggled with their knowledge regarding whether 'the loss of a distant or contentious relationship is easier to resolve than the loss of one which is close or intimate'. In addition, up to $48(75 \%)$ students did not know that 'the philosophy of palliative care is compatible with that of aggressive treatment' and that 'during the terminal stages of an illness, drugs that can cause respiratory depression are appropriate for the treatment of severe dyspnea'.

The total number of correct responses to the individual questions on the PCQN questionnaire before and after the course is shown on table 2, with the overall percentages in bracket. The correct response to each question is also presented.

Table 2. Correct and incorrect responses on the PCQN before and after the course.

\begin{tabular}{|c|c|c|c|c|c|c|}
\hline \multirow{3}{*}{ SN } & \multirow{3}{*}{ Questions } & \multirow{3}{*}{$\begin{array}{l}\text { Correct } \\
\text { answer }\end{array}$} & \multicolumn{4}{|c|}{$\begin{array}{l}\text { Number of correct and incorrect responses } \\
\text { before and after the course }\end{array}$} \\
\hline & & & \multicolumn{2}{|c|}{ Before $(n=69)(\%)$} & \multicolumn{2}{|c|}{ After $(n=64)(\%)$} \\
\hline & & & Correct & Incorrect & Correct & Incorrect \\
\hline 1 & $\begin{array}{l}\text { Palliative care is only appropriate in a situation where there is evidence of a } \\
\text { downhill trajectory or deterioration }\end{array}$ & False & $28(40.6)$ & $41(59.4)$ & $55(85.9)$ & $9(14.1)$ \\
\hline 2 & Morphine is the standard used to compare the analgesic effect of other opioids & True & $33(47.8)$ & $36(52.2)$ & $59(92.2)$ & $10(15.6)$ \\
\hline 3 & The extent of the disease determines the method of pain treatment & False & $6(8.7)$ & 63(91.3) & $21(32.8)$ & $43(67.2)$ \\
\hline 4 & Adjuvant therapies are important in managing pain & True & $34(49.3)$ & $35(50.7)$ & $59(92.2)$ & $10(15.6)$ \\
\hline 5 & It is crucial for family members to remain at the bedside until death occurs & False & $13(18.8)$ & $56(81.2)$ & $18(28.1)$ & $46(71.9)$ \\
\hline 6 & $\begin{array}{l}\text { During the last days of life, drowsiness associated with electrolyte imbalance } \\
\text { may decrease the need for sedation }\end{array}$ & True & $36(52.2)$ & $33(47.8)$ & $44(68.7)$ & $20(31.3)$ \\
\hline 7 & $\begin{array}{l}\text { Drug addiction is a major problem when morphine is used on a long-term basis } \\
\text { for the management of pain }\end{array}$ & False & $4(5.8)$ & $65(94.2)$ & $20(31.3)$ & $44(68.7)$ \\
\hline 8 & Individuals who are taking opioids should also follow a bowel regime & True & 13(18.8) & $56(81.2)$ & $55(85.9)$ & $9(14.1)$ \\
\hline 9 & The provision of palliative care requires emotional detachment & False & $40(58.0)$ & $29(42.0)$ & $38(59.4)$ & $26(40.6)$ \\
\hline 10 & $\begin{array}{l}\text { During the terminal stages of an illness, drugs that can cause respiratory } \\
\text { depression are appropriate for the treatment of severe dyspnea }\end{array}$ & True & $8(11.6)$ & 61(88.4) & $16(25.0)$ & $48(75.0)$ \\
\hline 11 & Men generally reconcile their grief more quickly than women & False & $8(11.6)$ & $61(88.4)$ & $20(31.3)$ & 44(68.7) \\
\hline 12 & The philosophy of palliative care is compatible with that of aggressive treatment & True & $3(4.3)$ & $66(95.7)$ & $16(25.0)$ & $48(75.0)$ \\
\hline 13 & The use of placebos is appropriate in the treatment of some types of pain & False & $0(0.00)$ & $69(100)$ & $31(48.4)$ & $33(51.6)$ \\
\hline 14 & In high doses codeine causes more nausea and vomiting than morphine & True & 12(17.4) & $57(82.6)$ & $38(59.4)$ & 26(40.6) \\
\hline 15 & Suffering and physical pain are synonymous & False & $38(55.1)$ & $31(44.9)$ & $50(78.1)$ & 14(21.9) \\
\hline 16 & Tramadol is not an effective analgesic for the control of chronic pain & True & $10(14.5)$ & $59(85.5)$ & $46(71.9)$ & $18(28.1)$ \\
\hline 17 & $\begin{array}{l}\text { The accumulation of losses renders burnout inevitable for those who work in } \\
\text { palliative care }\end{array}$ & False & $16(23.2)$ & $53(76.8)$ & $21(32.8)$ & $43(67.2)$ \\
\hline
\end{tabular}




\begin{tabular}{|c|c|c|c|c|c|c|}
\hline \multirow{3}{*}{ SN } & \multirow{3}{*}{ Questions } & \multirow{3}{*}{$\begin{array}{l}\text { Correct } \\
\text { answer }\end{array}$} & \multicolumn{4}{|c|}{$\begin{array}{l}\text { Number of correct and incorrect responses } \\
\text { before and after the course }\end{array}$} \\
\hline & & & \multicolumn{2}{|c|}{ Before $(n=69)(\%)$} & \multicolumn{2}{|c|}{ After $(n=64)(\%)$} \\
\hline & & & Correct & Incorrect & Correct & Incorrect \\
\hline 18 & Manifestations of chronic pain are different from those of acute pain & True & $63(91.3)$ & $6(8.7)$ & $64(100)$ & $0(0.00)$ \\
\hline 19 & $\begin{array}{l}\text { The loss of a distant or contentious relationship is easier to resolve than the loss } \\
\text { of one that is close or intimate }\end{array}$ & False & $6(8.7)$ & $63(91.3)$ & $14(21.9)$ & $50(78.1)$ \\
\hline 20 & Pain thresholds is lowered by fatigue or anxiety & True & $34(49.3)$ & $35(50.7)$ & $42(65.6)$ & $22(34.4)$ \\
\hline
\end{tabular}

McNemars test was used to assess the proportion of students who knew before to the proportion of students who knew after. Much specifically, it assessed whether the number of students who did not know the correct answer before but knew it after (students who improved) was greater than the number of students who knew the correct answer before but did not know it after (students who deteriorated). The result from this analysis indicated a highly significant improvement for most of the individual questions on the
PCQN $(\mathrm{P}<.05)$ (Table 3).

However, the questions: 'It is crucial for family members to remain at the bedside until death occurs' (question 5; $\mathrm{P}=.286$ ), 'the provision of palliative care requires emotional detachment' (question 9; $\mathrm{P}=1.0$ ), and 'the accumulation of losses renders burnout inevitable for those who work in palliative care' (question $17 ; \mathrm{P}=.383$ ) indicated no significant improvement.

Table 3. Students' pre and post course palliative care knowledge scores for the individual items of the PCQN.

\begin{tabular}{|c|c|c|c|c|c|}
\hline \multicolumn{6}{|l|}{ Answer known before/after palliative care course } \\
\hline Item & Yes/yes & Yes/No & No/Yes & No/No & P-value \\
\hline $\begin{array}{l}\text { Palliative care is only appropriate in a situation where there is evidence of a } \\
\text { downhill trajectory or deterioration }\end{array}$ & $24(37.5 \%)$ & $2(3.1 \%)$ & $31(48.4 \%)$ & $7(10.9 \%)$ & $0.000 * * *$ \\
\hline Morphine is the standard used to compare the analgesic effect of other opioids & $30(46.9 \%)$ & $1(1.6 \%)$ & $29(45.3 \%)$ & $4(6.25 \%)$ & $0.000 * * *$ \\
\hline The extent of the disease determines the method of pain treatment & $2(3.1 \%)$ & $2(3.1 \%)$ & $19(29.7 \%)$ & $41(64.1 \%)$ & $0.000 * * *$ \\
\hline Adjuvant therapies are important in managing pain & $31(48.4 \%)$ & $1(1.6 \%)$ & $27(42.2 \%)$ & $5(7.8 \%)$ & $0.000 * * *$ \\
\hline It is crucial for family members to remain at the bedside until death occurs & $4(6.25 \%)$ & $8(12.5 \%)$ & $14(21.9 \%)$ & $38(59.4 \%)$ & 0.286 \\
\hline $\begin{array}{l}\text { During the last days of life, drowsiness associated with electrolyte imbalance may } \\
\text { decrease the need for sedation }\end{array}$ & $26(40.6 \%)$ & $8(12.5 \%)$ & $18(28.1 \%)$ & $12(18.8 \%)$ & $0.076^{*}$ \\
\hline $\begin{array}{l}\text { Drug addiction is a major problem when morphine is used on a long-term basis } \\
\text { for the management of pain }\end{array}$ & - & $4(6.25 \%)$ & $20(31.2 \%)$ & $40(62.5 \%)$ & $0.002 * * *$ \\
\hline Individuals who are taking opioids should also follow a bowel regime & $11(17.2 \%)$ & $2(3.1 \%)$ & $44(68.8 \%)$ & $7(10.9 \%)$ & $0.000 * * *$ \\
\hline The provision of palliative care requires emotional detachment & $27(42.2 \%)$ & $11(17.2 \%)$ & $11(17.2 \%)$ & $15(23.4 \%)$ & 1.000 \\
\hline $\begin{array}{l}\text { During the terminal stages of an illness, drugs that can cause respiratory } \\
\text { depression are appropriate for the treatment of severe dyspnea }\end{array}$ & $4(6.25 \%)$ & $3(4.7 \%)$ & $12(18.8 \%)$ & $45(70.3 \%)$ & $0.035^{* *}$ \\
\hline Men generally reconcile their grief more quickly than women & $2(3.1 \%)$ & $5(7.8 \%)$ & $18(28.1 \%)$ & $39(60.9 \%)$ & $0.011 * *$ \\
\hline The philosophy of palliative care is compatible with that of aggressive treatment & $1(1.6 \%)$ & $2(3.1 \%)$ & $15(23.4 \%)$ & $46(71.9 \%)$ & $0.002 * * *$ \\
\hline The use of placebos is appropriate in the treatment of some types of pain & - & - & $31(48.4 \%)$ & $33(51.6 \%)$ & - \\
\hline In high doses codeine causes more nausea and vomiting than morphine & $8(12.5 \%)$ & $3(4.7 \%)$ & $30(46.9 \%)$ & $23(35.9 \%)$ & $0.000 * * *$ \\
\hline Suffering and physical pain are synonymous & $26(40.6 \%)$ & $8(12.5 \%)$ & $24(37.5 \%)$ & $6(9.4 \%)$ & $0.007 * *$ \\
\hline Tramadol is not an effective analgesic for the control of chronic pain & $7(10.9 \%)$ & $2(3.1 \%)$ & $39(60.9 \%)$ & $16(25 \%)$ & $0.000 * * *$ \\
\hline $\begin{array}{l}\text { The accumulation of losses renders burnout inevitable for those who work in } \\
\text { palliative care }\end{array}$ & $8(12.5 \%)$ & $8(12.5 \%)$ & $13(20.3 \%)$ & $35(54.7)$ & 0.383 \\
\hline Manifestations of chronic pain are different from those of acute pain & $59(92.2 \%)$ & - & $5(7.8 \%)$ & - & - \\
\hline $\begin{array}{l}\text { The loss of a distant or contentious relationship is easier to resolve than the loss of } \\
\text { one that is close or intimate }\end{array}$ & $3(4.7 \%)$ & $3(4.7 \%)$ & $11(17.2 \%)$ & $47(73.4 \%)$ & $0.057^{*}$ \\
\hline Pain thresholds is lowered by fatigue or anxiety & $19(29.7 \%)$ & $4(6.25 \%)$ & $23(35.9 \%)$ & $18(28.1 \%)$ & $0.00 * * *$ \\
\hline
\end{tabular}

$* * *$ P-Value $<0.01$ (Significant at 1\%); **P-Value $<0.05$ (Significant at 5\%; *P-Value $<0.1$ (Significant at 10\%).

Source: Author's Calculation.

\subsection{Predictors of Students' Palliative Care Knowledge and Change in Knowledge}

Six demographic factors were examined for their influence on students' pre-course (pretest) palliative care knowledge scores. Students' level in the nursing course and age were seen to be associated with students' pre-course scores $(\mathrm{P}=0.002$ and 0.027 respectively). Third year nursing students had a higher mean score of 6.58 compared to second year students who had a mean score of 4.68. In addition, students who were aged 21 and above had a higher mean score of 6.35 , compared to those who were aged 18 -
20 who had a mean score of 5.00. The other 4 demographic variables were not found to influence students' pre-course knowledge. They included; previous palliative care education, previous experience in the care of the dying, gender, and region.

These demographic factors were also examined for their influence on the post-course (posttest) palliative care knowledge scores. There was no association between any of these demographic variables and the post-course scores $(\mathrm{P}>0.05)$. 


\section{Discussion}

The findings suggest these students had very poor precourse palliative care knowledge. However, after participating in the course, they generally experienced significant improvements in their palliative care knowledge.

The mean pretest knowledge score was very low (5.72/20 on the PCQN scale). This finding echoes those of other studies in the literature, in which students demonstrated very poor palliative care knowledge. For example, Pope [12] in the Southeastern United States University found the mean palliative care knowledge score on the PCQN of junior and senior level nursing students to be 11.7 and 12.9 respectively. In Canada, Brajtman et al. [13] using the PCQN also reported a mean palliative care knowledge score of 12.29. In Jordan, which is a resource-poor context like Cameroon, Qadire [14] recorded poor palliative care knowledge among nursing students on the PCQN scales, with a mean of 8.0. These justify the widely shared views, in the literature, that preregistration nursing students generally lack palliative care competencies.

The findings of this study also corroborates the findings of the study by Qadire [14] of poor knowledge of the principles of palliative care among nursing students. An understanding of the meaning and philosophy of palliative care is vital to effective palliative care practice [15], and thus needs to be emphasized in palliative care courses. More so, the pretest survey also revealed poor knowledge regarding the use of placebos in pain management. This resonates with the wider literature, which suggests that some health care practitioners lack trust in patients' pain reports, and thus often use placebos as a test for pain 'reality'. This practice is deceptive, unethical and unacceptable and has been strongly discouraged by pain management experts. This is because pain perception is subjective, and there is often an expected patients' positive response to a placebo [16]. There was also a lack of understanding with regards to the use of morphine in pain management, in palliative care. Many other studies have similarly found misconceptions about morphine, both among nursing students and qualified nurses [11-12, 17-19]. These often results in poor pain management for patients [20-21], and therefore needs to be appropriately addressed in palliative care educational programs.

There was a significant improvement in the overall palliative care knowledge base of this student group after the course. This finding supports findings from previous studies that palliative care education is beneficial in improving the palliative care knowledge of preregistration nursing students $[4-5,22]$.

This study, like some comparative studies in the literature found improvements in students' knowledge relating to pain management [17-19]. Studies with qualified nurses, have also reported improvements in nurses' knowledge of pain management [23-24].

Although overall there was improvement in the palliative care knowledge base of this student group, there were still some areas of palliative care where students still experienced difficulties. For example, the posttest scores showed that students still had difficulty in understanding that the philosophy of palliative care is compatible with that of aggressive treatment. Nevertheless, it seems the wording of this item was a problem. Like Arber [19], the authors of this study think that the term 'aggressive treatment' might have been unclear to the students and might need to be revised as 'compatible with disease specific treatments like cancer therapy and antiretroviral drugs' [25] or compatible with 'active total care' as is commonly used in the UK [19]. In addition, students still struggled with their knowledge of psychosocial and spiritual care. In the posttest survey, a good number of these students did not change their views in 3 main items that relate to psychosocial and spiritual care. This finding is however different from that of Arber [19] in the UK and Kwekkeboom et al. [26] in the USA, who recorded improvements in knowledge of psychosocial and spiritual care, after a palliative care educational intervention. This discrepancy might be attributable to the differences in cultural and psychosocial attitudes to death and dying. It is worth noting that in Cameroon most families are extended families with stronger familial ties. The family is a significant part of the care team and family caregivers often assist nurses in performing some activities that are exclusively nursing roles in western societies. Family members will often bath and feed patient and even administer oral medications. Moreover, family members will often converge at the bedside of a dying person when the prognosis of dying is pronounced. This is often considered by both the family and the dying person as an opportunity for discussing the will, saying goodbye and accompanying the dying. This family dynamics might explain why after the course students still felt it is crucial for family members to remain at the bedside until death occurs and that it is easier to resolve the loss of one that is not close or intimate. This finding is similar to the findings of the study by Kim et al. [27], with qualified nurses in Korea, who did not change their views about the need for family members to remain at the bedside until death occurs, after attending an ELNEC course. Kim et al. [27] also attributed this observation to the Korean culture. These findings corroborates the views and recommendations by Ingleton et al., [28] that education alone cannot be sufficient to effect culture change among health professionals, requiring initiatives that can more effectively moderate attitudes and behaviours.

This study only utilised a volunteer sample from one university, which together with the quasi-experimental design limits the generalisability of the study findings to the general population of preregistration student nurses in Cameroon [2930]. In addition, although the observed improvements in students' palliative care knowledge may be ascribed to the palliative care course in a causal relationship, the lack of a control group cannot permit a true estimation of this impact. Thus the conclusions of this study should be taken with caution.

\section{Conclusion}

Preregistration nursing students of the pilot University in Cameroon have a huge need for palliative care education, 
which reflects a general need by all preregistration nursing students in the country. A palliative care course for preregistration student nurses in Cameroon, delivered by nurse educators and specialist palliative care nurses in Cameroon has the potential to improve preregistration student nurses' palliative care knowledge. These findings contribute to the existing body of literature and support the value of integrating palliative care into preregistration nurse training curricula in resource-poor countries.

\section{References}

[1] Payne, S., Seymour, J. and Ingleton, C. (2009) The role of the nurse in palliative care setting in the global context. Cancer Nursing Practice 8 (5): 21-26.

[2] Mwangi-Powell, F. and Dix, O. (2011) Palliative care in Africa: an overview. Africa Health: 19-21.

[3] Gwyther, L. (2007) Africa. In Wee, B and Hughes, N (eds.) Education in Palliative Care Building a Culture of Learning. Oxford University Press, Oxford. pp. 43-48.

[4] Bassah, N., Seymour, J., and Cox, K. (2014) A modified systematic review of research evidence about education for pre-registration nurses in palliative care. BMC Palliative Care 13:56 [Online] Available from:

http://www.biomedcentral.com/147-684X/13/56 [Accessed $20^{\text {th }}$ December 2014].

[5] Cavaye, J. and Watts, J. H. (2014) An Integrated Literature Review of Death Education in Pre-Registration Nursing Curricula: Key Themes. International Journal of Palliative Care.

[6] Cavaye, J. and Watts, J. H. (2012) End-of-life education in the pre-registration nursing curriculum: Patient, carer, nurse and student perspectives. Journal of Research in Nursing 17 (4): 317-326.

[7] Cassidy, S. (2009): Interpretation of competence in student assessment. Nursing Standard 23:39-46.

[8] Cowan, D., Norman, I. and Coopamah. V. (2005) Competence in nursing practice: A controversial concept - A focused review of literature. Nurse Education Today 25 (5): 355-362.

[9] Kolb, D. A. Experiential learning: Experience as the source of learning and development. New Jersey: Prentice-Hall; 1984.

[10] Polgar, S. and Thomas, S. (2008) Research in the health sciences. 5th ed. Livingstone, Churchill.

[11] Ross, M., McDonald, B. and McGuinness, J. (1996) The palliative care quiz for nursing (PCQN): the development of an instrument to measure nurses' knowledge of palliative care. Journal of Advance Nursing 23 (1): 126-37.

[12] Pope, A. (2013) Palliative Care Knowledge among Bachelors of Science Nursing Students. Dissertations, Theses and Capstone Projects. Paper 596. Kennesaw State University.

[13] Brajtman, S., Higuchi, K., Murray, M. A. Developing meaningful learning experiences in palliative care nursing education. International Journal of Palliative Nursing. 2009; $15: 327-331$.
[14] Qadire, M. (2014) Knowledge of palliative care: An online survey. Nurse Education Today 34 (5): 714-718.

[15] Worldwide Palliative Care Alliance, 2014. Global Atlas of Palliative Care at the End of Life. http://www.who.int/nmh/Global_Atlas_of_Palliative_Care.pdf

[16] Brown, C. and Christo, P. J. (2011) Importance of placebo effect in Pain management. In Vadivelu N, Urman RD, Hines RL (eds.) Essentials of pain management. Springer, New York pp. 189-201.

[17] Broglio, K. (2014) Pilot of an online introduction to palliative care for nurses. Journal of Hospice and Palliative Nursing 16(17):420-429.

[18] El-Nagar, S. and Lawend, J. (2013) Impact of Palliative Care Education on Nurses' Knowledge, Attitude and Experience Regarding Care of Chronically Ill Children. Journal of Natural Sciences Research 3 (11): 94-103.

[19] Arber, A. (2001) Student nurses' knowledge of palliative care: evaluation of an education module. International Journal of Palliative Care Nursing 7 (12): 597-603.

[20] Becker, R. (2010) Fundamental Aspects of Palliative Care Nursing: an evidence based handbook for student nurses. 2nd Edn. Quay Books, London.

[21] Edwards, H. E, Nash, R. E., Najman, J. M., Yates, P. M., Fentiman, B. J., Dewar, A, et al (2001). Determinants of nurses' intension to administer opiods for pain relief. Nurs Health Sci. 3 (3): 149-59.

[22] Frey, R., Gott, M. and Neil, H. (2012) Instruments used to measure the effectiveness of palliative care education initiatives at the undergraduate level: a critical literature review. BMJ Supportive \& Palliative Care 3 (1): 114-119.

[23] Morita, T., Fujimoto, K., Imura, C., Nanba, M., Fukumoto, N. and Itoh, T. (2006): Self-reported Practice, Confidence, and Knowledge About Palliative Care of Nurses in a Japanese Regional Cancer Center: Longitudinal Study After 1-Year Activity of Palliative Care Team. AM J HOSP PALLIAT CARE 23 (5): 385-391.

[24] Adriaansen, M. J., van Achterberg, T., and Borm, G. (2005). Effects of a postqualification course in palliative care. Journal of Advanced Nursing 49(1):96-103.

[25] Lavy, V. and Wooldridge R. (2008) Palliative Care toolkit: improving care from the roots up in resource-limited settings [online]. Available from: http://www.helpthehospices.org.uk [Accessed $20^{\text {th }}$ January 2013].

[26] Kwekkeboom, K., Vahl, C., and Eland, J. (2006) Impact of volunteer companion program on nursing students' knowledge and concerns related to palliative care. Journal of Palliative Medicine 9 (1): 90-99.

[27] Kim, H. S., Kim, B. H., Yu, S. J., Kim, S., Park, S. H., Choi, S., and Jung, Y. (2011) The Effect of an End-of-Life Nursing Education Consortium course on nurses' knowledge of hospice and palliative care in Korea. Journal of Hospice and Palliative Nursing 13 (4): 222-229.

[28] Ingleton, C., Gardiner, C., Seymour, J., Richards, N. and Gott, M. (2013) Exploring education and training needs among the palliative care workforce. BMJ Supportive and Palliative Care 0:1-6 doi: 10.1136/bmjspcare-2013-000233. 
[29] Barnes, J., Conrad, K., Demont-Heinrich, C., Graziano, M., et al. (2012) Generalizability and Transferability. Writing@CSU. Colorado State University. Available from $\mathrm{http}: / /$ writing.colostate.edu/guides/guide.cfm?guideid $=65$ [Accessed: Accessed 6 ${ }^{\text {th }}$ September 2014].
[30] Polit, D. F. and Beck, C. T. (2010) "Generalization in quantitative and qualitative research: Myths and strategies," International Journal of Nursing Studies 47: 1451-1458. 